\title{
Construire, reconstruire, aménager le château en
} Normandie

\section{Michel Biard}

\section{(2) OpenEdition \\ 1 Journals}

\section{Édition électronique}

URL : https://journals.openedition.org/ahrf/2031

DOI : 10.4000/ahrf.2031

ISSN : 1952-403X

Éditeur :

Armand Colin, Société des études robespierristes

\section{Édition imprimée}

Date de publication : 1 juin 2005

Pagination : 211-213

ISSN : 0003-4436

\section{Référence électronique}

Michel Biard, "Construire, reconstruire, aménager le château en Normandie », Annales historiques de la Révolution française [En ligne], 340 | avril-juin 2005, mis en ligne le 20 avril 2006, consulté le 24 avril 2022. URL : http://journals.openedition.org/ahrf/2031 ; DOI : https://doi.org/10.4000/ahrf.2031

Ce document a été généré automatiquement le 24 avril 2022.

Tous droits réservés 


\title{
Construire, reconstruire, aménager le château en Normandie
}

\author{
Michel Biard
}

\section{RÉFÉRENCE}

Jean-Paul HERVIEU, Gilles DÉSIRÉ dit GOSSET et Éric BARRÉ (dir.), Construire, reconstruire, aménager le château en Normandie, Caen, Annales de Normandie, 2004, 368 p., ISBN 2-902239-13-0, $35 €$.

1 Ce sont les actes du 38e congrès de la Fédération des sociétés historiques et archéologiques de Normandie, tenu à Domfront en octobre 2003, qui sont ici rassemblés. Après quelques pages visant à orienter de futures recherches et à fournir des indications bibliographiques, cet ouvrage se subdivise en plusieurs parties: le château médiéval; annexes et dépendances du château; les châteaux des Lumières; images et imaginaires du château ; restauration et rénovation des châteaux ; le château à l'époque révolutionnaire ; le château à l'époque contemporaine.

2 Trois communications évoquent les transformations subies par les châteaux au XVIIIe siècle : celle d'Aline Lemonnier-Mercier sur un riche financier, Jules-David Cromot, qui acquiert le domaine de Bourg-Saint-Léonard (Orne) où se trouve un château ancien et qui, entre 1763 et 1767, entreprend de faire édifier un château plus digne d'un « homme des Lumières "; celle de Christophe Morin à propos du château de Dangu dans l'Eure (avec une question centrale présente dans le titre: "comment faire d'un château médiéval une maison de plaisance moderne ?») ; celle de Pierre Pajot sur le château de Saint-Just-près-Vernon (Eure) appartenant au duc de Penthièvre, qui le fait aménager en hôpital-hospice pour recevoir pauvres et infirmes. La communication d'Erwan Patte est pour sa part consacrée à "deux chantiers de l'époque des Lumières en BasseNormandie », le château de Bénouville (Calvados), œuvre de l'architecte Claude-Nicolas Ledoux, et celui de Pont-Rilly à Négreville (Manche), tous deux édifiés dans les années 1770. Enfin, Sophie Poirier-Haudebert propose au lecteur un parcours dans le 
département de la Manche, avec notamment le château de Saint-Pierre-Église, sur le thème de "la façade, un instrument de valorisation sociale ", le tout illustré par une série de photos qui témoignent de cette ostentation sociale recherchée.

La partie réservée à la période révolutionnaire pourra apparaître fort mince, avec seulement deux communications. Pour autant, ces textes sont intéressants, aussi convient-il de les mentionner dans les A.H.R.F. Tout d'abord, sous le titre «Châteaux de l'Eure en Révolution ", Bernard Bodinier rappelle les décrets qui peu à peu ont fait disparaître les droits des seigneurs et donne divers exemples des troubles antiféodaux qui ont touché le département de l'Eure, notamment le cas du saccage du château de La Chapelle-Bayvel en septembre 1792. À cette date, évidemment, comme ailleurs, ce n'est plus simplement au seigneur en tant qu'« oppresseur » que s'en prennent les émeutiers, mais au suspect potentiel. Comme le propriétaire, Nicolas Antoine de Giverville, aurait été vu à Rouen en train de s'embarquer pour quitter le pays avec plusieurs dizaines de prêtres réfractaires; la rumeur enfle et la sentence populaire tombe : « il n'a plus besoin de château »! Plus de trois cents personnes investissent son château, pillent, brûlent mobilier et lambris dans le même autodafé qui consume les archives seigneuriales, avant que l'incendie ne gagne le bâtiment tout entier. Plusieurs des émeutiers sont arrêtés quelques semaines plus tard et ce n'est qu'en mars 1793 que leur procès a lieu, après cinq mois de détention. Trois hommes sont condamnés à 6 ou 9 ans de fer. Deux d'entre eux ayant été jugés comme contumaces, seul un des captifs peut être attaché sur un échafaud à Pont-Audemer et "exposé aux regards du peuple pendant six heures » par une justice qui se voulait encore exemplaire. Naturellement, le grand spécialiste des biens nationaux qu'est Bernard Bodinier ne pouvait manquer de préciser le sort des châteaux de l'Eure confisqués et vendus comme biens nationaux de seconde origine : 74 au total, dont 34 en 1794-1795, 34 autres entre 1796 et 1799, 2 en 1800 et 4 en 1810 (mais si l'on considère ensemble les trois premières années, 1794-1795-1796, ce sont trois quarts des ventes qui sont réalisées). On trouvera dans cette communication d'utiles détails sur ces ventes et la conclusion suivante: «On a souvent accusé la Révolution de vandalisme. De fait, abbayes et couvents ont souvent servi de carrières de pierre ; du mobilier et des œuvres d'art ont été dispersés [...] en revanche [... la Révolution] n'a pas détruit de châteaux en Haute-Normandie (un seul dans l'Eure et pas davantage en Seine-Inférieure). Si de nombreux châteaux ont disparu par la suite, c'est en raison des agissements de leurs acquéreurs ou de l'impécuniosité de leurs propriétaires ». Cette analyse est confirmée par la seconde communication, due à la plume d'André Goudeau, sous le titre: "Acquérir et démolir le château sous la Révolution : l'exemple de Lemercier ». Ce Louis Pierre François Lemercier, marchand de bois de Caudebec-les-Elbeuf, a de fait un profil exemplaire de spéculateur. Il acquiert en effet deux châteaux, celui de La Londe en Seine-Inférieure, acheté via un prête-nom en brumaire an III, et celui de Montaure dans l'Eure en frimaire an III. C'est dire qu'en à peine deux mois de temps, ce marchand de bois avait acheté une belle quantité de pierre! Mieux, il achète un troisième château, celui de Bizy dans l'Eure en prairial an VI. De marchand de bois à marchand de pierre, il n'y a qu'un pas, aussi l'heureux propriétaire fait-il démolir deux de ses trois "demeures" pour récupérer les matériaux et les vendre. Tour à tour, au gré des ventes de pierre, brique, plomb, boiseries, etc., La Londe et Bizy sont rayés de la carte. Seul le château de Montaure devait subsister, sans doute utilisé par le nouveau propriétaire comme une résidence secondaire où il pouvait afficher ses prétentions de parvenu en quête de notabilité. Si l'on ajoute que Lemercier a participé à la dévastation des bois et forêts, André Goudeau nous offre ici un "beau" 
portrait de ces hommes qui mirent à profit la Révolution pour leur intérêt particulier et non pour défendre l'intérêt général. Pour le goût du détail, signalons que Lemercier, administrateur dans la municipalité de canton d'Elbeuf sous le Directoire, fut suspendu de ses fonctions pour faux en écriture et abus de confiance... il avait été dénoncé aux autorités du département le 26 brumaire an VIII, quelques jours après que le coup d'État de Bonaparte eut ouvert la voie qui allait « terminer la Révolution » et consolider le pouvoir des élites sociales.

4 Si l'on ajoute que la plupart des autres communications de ce congrès sont souvent dignes d'intérêt, même si la spécificité des A.H.R.F. m'incite à ne pas en donner ici un compte rendu détaillé, il va de soi que ce bel ouvrage devrait obtenir un écho dépassant largement les seuls départements normands. 